\title{
RUÍDO ESCOLAR E SUA IMPLICAÇÃO NA ATIVIDADE DE DITADO
}

\section{Influence of school noise on dictation activity}

\author{
Graziela Cambruzzi Jaroszewski $^{(1)}$, Bianca Simone Zeigelboim ${ }^{(2)}$, Adriana Lacerda ${ }^{(3)}$
}

\begin{abstract}
RESUMO
Objetivo: avaliar o nível de ruído nas salas de aula de primeira série do ensino fundamental, bem como verificar sua interferência durante as atividades de leitura e ditado. Métodos: realizou-se a medição dos níveis de ruído segundo padrões ANSI em sete salas de aula de cinco escolas da rede municipal de ensino da cidade de Urussanga/SC durante as atividades de leitura e ditado. Posteriormente aplicou-se um questionário aos alunos e professores abordando a interferência do ruído nas atividades realizadas. Participaram da pesquisa 109 crianças sendo, 59 do gênero masculino e 50 do gênero feminino. Resultados: os níveis de ruído presentes nas salas de aulas, variou de 59,5 a 71,3 $\mathrm{dB}(\mathrm{A})$. Quanto à percepção dos alunos e professores sobre o ruído, 94,5\% dos alunos e $100 \%$ dos professores perceberam outras fontes sonoras durante as atividades, mas, apenas $52,39 \%$ dos alunos e 42,8\% dos professores afirmaram interferência do ruído na aplicação das atividades. Conclusão: observou-se que o nível de ruído mesmo estando acima do proposto pelas normas nacionais, não interferiu no resultado do ditado. Por outro lado, os professores, principalmente das salas mais ruidosas, necessitaram elevar a voz durante a aplicação da atividade, queixando-se posteriormente de cansaço vocal.
\end{abstract}

DESCRITORES: Ruído; Percepção do Ruído; Efeitos do Ruído; Aprendizagem

\section{INTRODUÇÃO}

Diversos estudos sobre questões biológicas e cognitivas envolvidas com o ensino referem que a aprendizagem não depende somente de técnicas pedagógicas, mas também de boas condições acústicas. Dessa maneira, durante o processo de aprendizagem, faz-se necessário que a mensagem emitida pelo professor seja recebida de forma clara pelo aluno. Em uma situação desfavorável em que há competição entre a fala do professor e os demais ruídos, o desempenho escolar pode sofrer interferência ${ }^{1,2}$.

(1) Fonoaudióloga da Prefeitura de Urussanga - SC; Especializanda em Audiologia Clínica.

(2)

Fonoaudióloga; Docente da Universidade Tuiuti do Paraná; Coordenadora do Programa de Mestrado e Doutorado em Distúrbios da Comunicação da Universidade Tuiuti do Paraná; Doutora em Ciências dos Distúrbios da Comunicação Humana pela Universidade Federal de São Paulo.

(3) Fonoaudióloga; Docente da Universidade Tuiuti do Paraná; Mestre em Distúrbios da Comunicação pela Universidade Tuiuti do Paraná.
Fatores acústicos como: níveis de ruído de fundo, tempo de reverberação e a relação sinal-ruído, afetam diretamente a comunicação em sala de aula. Quando os alunos não podem ouvir devidamente a mensagem falada, a habilidade de compreensão pode ser afetada e, conseqüentemente, seu progresso de aprendizagem pode ser prejudicado ${ }^{3-5}$.

Nesse ambiente, os alunos podem desenvolver dificuldades em escrever, ler, manter atenção e concentração, resultando em problemas disciplinares. As crianças em fase de alfabetização são as mais prejudicadas, pois se encontram em uma etapa de aquisição de vocabulários oral e escrito e de leitura ${ }^{1,2}$. De igual modo, o professor também é afetado, pois necessita fazer ajustes na fala para projetar devidamente a sua voz e ser compreendido, aumentando as chances de desenvolver patologias vocais ${ }^{6-8}$.

Diferentes países, preocupados com a interferência do ruído no processo de aprendizagem, criaram normas ou decretos com o objetivo de estabelecer níveis de conforto acústico em salas de aula 9-13. Entretanto, apesar da existência dessas nor- 
mas, pesquisas nacionais e internacionais demonstram que os níveis de ruído nas escolas ultrapassam o valor máximo sugerido nas legislações vigentes para ambientes fechados, bem como, nas salas de aula podendo causar efeitos tanto sobre o aluno quanto sobre o professor ${ }^{1-4,14-19}$.

Pesquisas recentes sobre a percepção auditiva de alunos e professores, relacionados aos níveis de pressão sonora presentes nas escolas e suas implicações na prática escolar, revelam queixas relacionadas aos professores como; abuso vocal e interferência na concentração, e aos alunos como; dificuldade em ouvir o professor durante a aula e interferência na aprendizagem, trazendo dificuldades escolares ${ }^{16-18}$.

Portanto, muitas das dificuldades escolares podem estar relacionadas ao tipo de ruído a que os alunos estão expostos. Cada tipo de ruído afeta áreas diferentes do trabalho escolar. Aqueles que estão mais expostos ao ruído do tráfego (rodoviário, aeronaves ou trens) apresentam maior dificuldade na sua capacidade de evocar e descrever o conteúdo de um texto. Aqueles que estão expostos ao ruído verbal apresentam deterioração na capacidade de ler e aprender um texto ${ }^{20-24}$.

Os efeitos do ruído nas salas de aula poderiam ser evitados se algumas ações fossem realizadas, exemplo: oferecer tratamento acústico para as salas de aula, reduzindo-se assim, os ruídos externos e desenvolver campanhas de conscientização para a redução de ruídos na escola, dentro e fora das salas de aula ${ }^{3,15,18,19,25}$.

O presente estudo tem como objetivo, avaliar o nível de ruído nas salas de aula de primeira série do ensino fundamental, bem como verificar sua interferência durante as atividades de leitura e ditado.

\section{MÉTODOS}

Avaliou-se 123 crianças, em sete salas de aula de primeira série do ensino fundamental de cinco escolas (escolas A, B, C, D e E), da Rede Municipal de Ensino da Cidade de Urussanga/Santa Catarina.

Participaram todas as crianças que estavam presentes em sala de aula no momento do estudo. Catorze crianças foram excluídas da análise final, uma, por apresentar perda auditiva neurossensorial profunda; cinco, por não terem respondido ao questionário, oito, por não terem realizado o ditado. Dessa forma, 109 crianças participaram efetivamente do estudo, sendo 59 meninos e 50 meninas, na faixa etária de seis a oito anos. Além dos alunos, sete professores da primeira série das escolas avaliadas participaram da pesquisa.

A escola A localiza-se em um bairro próximo ao centro da cidade com poucas casas fazendo vizinhança. É a maior escola da rede municipal de ensino, possui 581 alunos. Essa escola é construída de alvenaria e as três salas avaliadas possuem portas de madeira e janelas de vidro, ventiladores de teto, carteiras com pés de ferro dispostas em cinco filas paralelas e teto com forração em PVC. As salas A1 e A2 apresentam piso cerâmico e três janelas com cortinas dispostas para os fundos de uma sala de aula; a sala A3 apresenta piso de madeira e duas janelas com cortinas, ficando uma à esquerda e uma à direita. Faz vizinhança com outras duas salas de aula. Essa escola faz recreio intercalado devido ao grande número de crianças.

A escola B possui 90 alunos, encontra-se em região do interior com apenas duas salas de aula. Faz vizinhança com um posto de saúde e está localizada próxima à rodovia SC-446. Essa escola é construída de alvenaria, a sala apresenta teto com forração de madeira, ventilador de teto, piso cerâmico e carteiras com pés de ferro dispostas em cinco filas paralelas. A escola possui duas janelas de vidros com cortinas, com acesso para o pátio da escola, e duas basculantes de madeira. A porta de madeira possui saída para o lavatório.

A escola $C$ é locada em um bairro afastado do centro, porém movimentado. Faz vizinhança com três ruas e possui 87 alunos. Sua construção é de alvenaria com piso de madeira, teto com forração de PVC, ventilador de teto, carteiras com pés de ferro sem uma posição fixa. Apresenta quatro janelas, duas dispostas para a rua e duas para o pátio da escola, além de uma porta de madeira disposta para o pátio. Essa escola faz o recreio das crianças intercalado, primeiro a educação infantil seguida do ensino fundamental.

A escola $D$, localizada em bairro afastado do centro da cidade, consta de 88 alunos no total. Também faz vizinhança com três ruas e, em suas proximidades encontra-se a rodovia SC-446. É a única escola com piso superior. Sua construção também é de alvenaria, com piso de madeira com carteiras de pés de ferro, sem uma disposição prédeterminada. A sala de aula avaliada possui teto de laje com quatro janelas de vidro e encortinadas, duas dispostas para a rua e duas para uma casa vizinha além de uma porta de madeira disposta para o pátio e ventilador de teto.

A escola E localizada em região do interior, faz vizinhança com uma rua cercada de área verde. Apresenta construção de alvenaria, teto com forração e piso de madeira. As carteiras apresentam pés de ferro e estão dispostas em cinco filas paralelas, possui ventilador de teto, porta de madeira para o pátio e duas janelas grandes de basculantes voltadas para o pátio da escola. 
Durante a aula de língua portuguesa, o professor realizou a leitura de um texto seguido de uma interpretação oral e de um ditado (Figura 1). As atividades foram realizadas pelo professor durante os 20 minutos intermediários (duração das aulas de 45 minutos), sendo descartados os 10 minutos iniciais e os 15 minutos finais. Enquanto as atividades eram aplicadas, a avaliação do nível de ruído ocorreu, utilizando-se o decibelímetro tipo $S$ 2AE, da marca Simpson, modelo 897, em conformidade com os padrões ANSI - S 1.4/1983 e ANSI - S 1.25/1978, de acordo com o método prescrito na Norma Brasileira Registrada (NBR) 10151: Avaliação do ruído em áreas habitadas visando o conforto da comunidade, da ABNT ${ }^{26}$.

$\mathrm{Na}$ escola A realizou-se a medida dos níveis de ruído em três salas de aula, uma no período matutino (A1) e duas no período vespertino (A2 e A3). As medições dos níveis de ruído das escolas $\mathrm{B}, \mathrm{C}, \mathrm{De}$ E ocorreram no período vespertino.

Após a conclusão das atividades, um questionário foi aplicado em conjunto com os alunos e, individualmente com os professores, com o objetivo de verificar a influência do ruído na atividade de ditado (Figuras 2 e 3 ).

A pesquisa foi aprovada pelo Comitê de Ética Institucional protocolo CEP 088/2006.

Aplicou-se o teste de Spearman com a finalidade de avaliar a correlação entre o nível de ruído presente em sala e a sua interferência no resultado (acertos e erros) no ditado dos alunos. Fixouse 0,05 ou $5 \%$ o nível de rejeição na hipótese de nulidade. Realizou-se análise descritiva dos questionários respondidos pelos alunos e professores das escolas.

\section{RESULTADOS}

Apresenta-se na Tabela 1 a distribuição dos resultados sobre os níveis médios de ruído das salas de aula e a porcentagem média de erros e acertos no ditado dos alunos. O nível médio de ruído observado variou entre 59.5 a $71.3 \mathrm{~dB}(\mathrm{~A})$.

Aplicou-se a correlação de Spearman que resultou em valor de $p=0,036238$ para os acertos e $p=0,534509$ para os erros. Considerando-se o nível de significância de $5 \%$, verificou-se que a correlação é significativa para os acertos pois $p<0,05$.

$\mathrm{Na}$ Tabela 2 os dados referem-se à percepção dos alunos em relação à presença de estímulos auditivos, além da voz do professor durante a ati- vidade do ditado. Nas escolas A2, A3, B e C, $100 \%$ dos alunos responderam afirmativamente a questão.

A Tabela 3 dispõe os estímulos sonoros percebidos pelos alunos além da voz do professor durante a atividade do ditado. Os estímulos sonoros mais referenciados foram: arrastar de mesas e cadeiras e pessoas conversando.

$\mathrm{Na}$ Tabela 4 estão expostos os dados referentes à percepção do nível de ruído dentro das salas de aula. Observou-se que os níveis mais considerados foram de baixo a médio.

A Tabela 5 refere-se à interferência do ruído da sala durante o desenvolvimento da atividade. Houve uma predominância de resposta afirmativa com relação à interferência do ruído apenas nas salas das escolas A2, A3, e B.

A Tabela 6 refere-se à compreensão das palavras do ditado. Notou-se a predominância de respostas afirmativas em todas as escolas, demonstrando assim, boa compreensão das palavras no ditado.

Na Tabela 7 observa-se como as crianças percebem a voz do professor. Houve predomínio de respostas dos alunos considerando a voz do professor adequada para o ambiente.

A Tabela 8 descreve os ruídos percebidos pelos professores durante o desenvolvimento da atividade do ditado. Os professores em sua totalidade referiram presença de outras fontes sonoras, sendo as mais referidas, o arrastar de mesas e cadeiras e pessoas conversando.

Quando questionados sobre a intensidade do ruído presente na sala de aula durante as atividades, cinco $(71,5 \%)$ dos professores das escolas A1, B, C, D e E consideraram o ruído como sendo de média intensidade, já dois $(28,5 \%)$ dos professores das escolas A2 e A3 consideraram o ruído como sendo de baixa intensidade. Porém, quando perguntados se o ruído interferia na aplicação destas atividades, três $(42,8 \%)$ dos professores das escolas A1, C e D responderam sim à questão.

Quanto à necessidade de mudança na intensidade vocal durante a aplicação das atividades de leitura e ditado, cinco $(71,5 \%)$ dos professores das escolas $A 1, A 2, A 3, B$ e $E$ responderam que não necessitaram aumentar a voz durante as atividades, somente dois $(28,5 \%)$ dos professores das escolas $\mathrm{C}$ e $\mathrm{D}$ responderam afirmativamente à questão, relatando cansaço vocal após as aulas. 
Tabela 1 - Correlação entre o nível de ruído e percentual de acertos e erros do ditado

\begin{tabular}{ccccc}
\hline \multirow{2}{*}{ Escolas } & $\begin{array}{c}\text { Número de } \\
\text { alunos }\end{array}$ & Nível Médio de Ruído & \multicolumn{2}{c}{ Ditado (\%) } \\
& 19 & 62.3 & Acertos & Erros \\
\hline A1 & 15 & 69.4 & 70,0 & 30,0 \\
A2 & 17 & 68.6 & 81,1 & 18,9 \\
A3 & 24 & 68 & 74,7 & 25,3 \\
B & 17 & 70.5 & 77,4 & 22,6 \\
C & 19 & 71.3 & 66,7 & 33,3 \\
D & 12 & 59.5 & 92,3 & 7,7 \\
E & 12 & 76,5 & 23,5 \\
\hline
\end{tabular}

A1 - Escola A sala 1; A2 - Escola A sala 2; A3 - Escola A sala 3; B - Escola B;

C - Escola C; D - Escola D; E - Escola E; dB(A) - Decibel

Correlação de Spearman: $R=0,785714$, valor de $p=0,036238$ para os acertos (estatisticamente significante) e $R=0,285714$, valor de $p=0,534509$ para os erros.

Tabela 2 - Percepção dos ruídos internos e externos pelos alunos durante a atividade de leitura de ditado

\begin{tabular}{|c|c|c|c|c|c|c|c|c|c|c|c|c|c|c|}
\hline \multirow{2}{*}{$\begin{array}{l}\text { PRESENÇA } \\
\text { DE RUÍDO }\end{array}$} & \multicolumn{2}{|c|}{$\begin{array}{c}\text { ESCOLA } \\
\text { A1 }\end{array}$} & \multicolumn{2}{|c|}{$\begin{array}{c}\text { ESCOLA } \\
\text { A2 }\end{array}$} & \multicolumn{2}{|c|}{$\begin{array}{c}\text { ESCOLA } \\
\text { A3 }\end{array}$} & \multicolumn{2}{|c|}{$\begin{array}{c}\text { ESCOLA } \\
\text { B }\end{array}$} & \multicolumn{2}{|c|}{$\begin{array}{c}\text { ESCOLA } \\
\text { C }\end{array}$} & \multicolumn{2}{|c|}{$\begin{array}{c}\text { ESCOLA } \\
\text { D }\end{array}$} & \multicolumn{2}{|c|}{$\begin{array}{c}\text { ESCOLA } \\
\text { E }\end{array}$} \\
\hline & $\mathrm{N}$ & $\%$ & $\mathrm{~N}$ & $\%$ & $\mathrm{~N}$ & $\%$ & $\mathrm{~N}$ & $\%$ & $\mathrm{~N}$ & $\%$ & $\mathrm{~N}$ & $\%$ & $\mathrm{~N}$ & $\%$ \\
\hline Sim & 18 & 94,7 & 14 & 100 & 16 & 100 & 23 & 100 & 15 & 100 & 10 & 76,9 & 7 & 77,8 \\
\hline Não & 1 & 5,3 & 0 & 0,0 & 0 & 0,0 & 0 & 0,0 & 0 & 0,0 & 3 & 23,1 & 2 & 22,2 \\
\hline Total & 19 & 100 & 14 & 100 & 16 & 100 & 23 & 100 & 15 & 100 & 13 & 100 & 9 & 100 \\
\hline
\end{tabular}

A1 - Escola A sala 1; A2 - Escola A sala 2; A3 - Escola A sala 3; B - Escola B; C-Escola C; D - Escola D; E - Escola E; $\mathrm{N}$ - Número de alunos. 
Tabela 3 - Ruídos percebidos pelos alunos durante as atividades de leitura e ditado

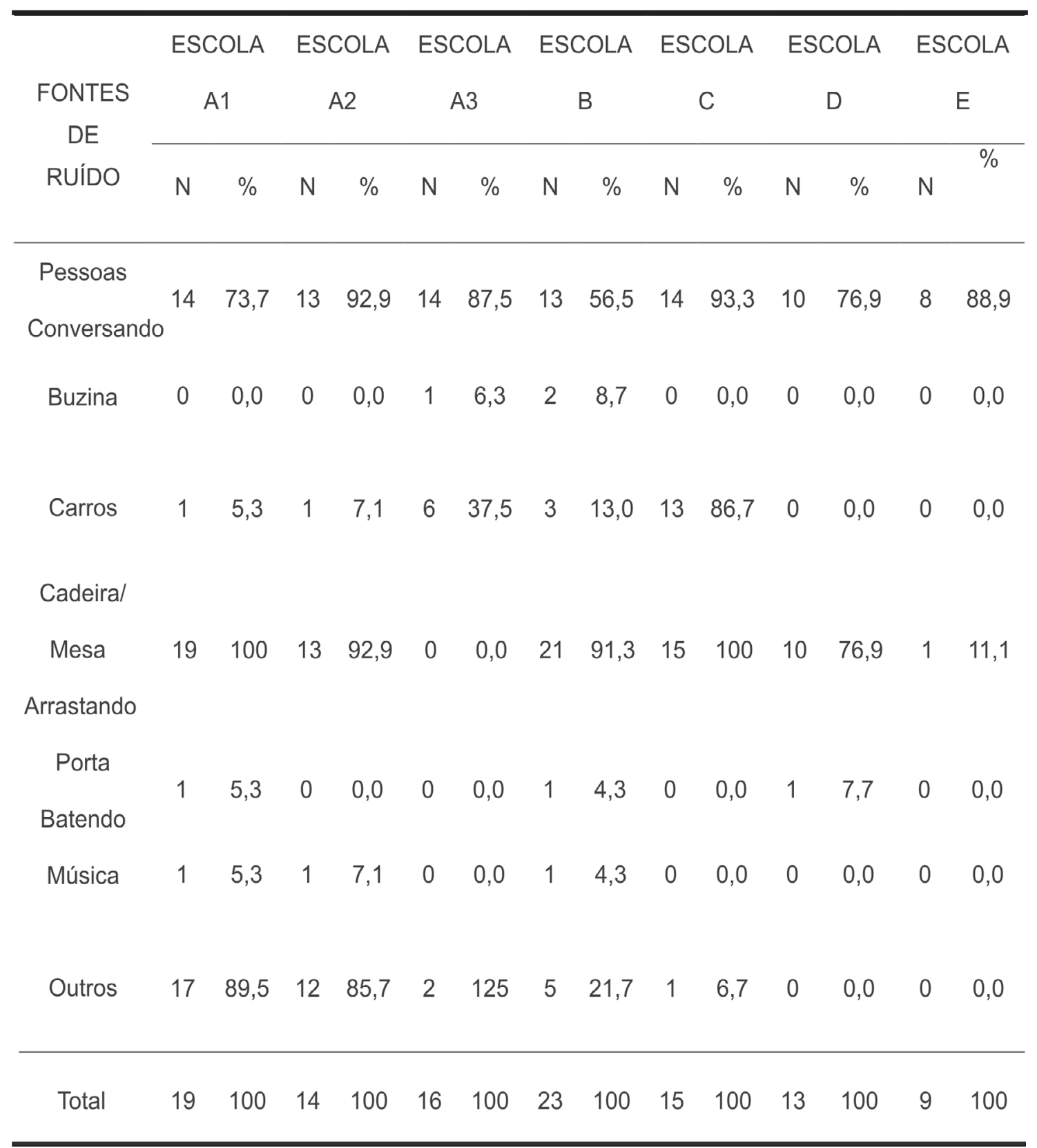

A1 - Escola A sala 1; A2 - Escola A sala 2; A3 - Escola A sala 3; B - Escola B;

C - Escola C; D - Escola D; E - Escola E; N - Número de alunos. 
Tabela 4 - Percepção auditiva da intensidade do ruído pelos alunos

\begin{tabular}{|c|c|c|c|c|c|c|c|c|c|c|c|c|c|c|}
\hline \multirow{2}{*}{$\begin{array}{l}\text { INTENSIDADE } \\
\text { DO RUÍDO }\end{array}$} & \multicolumn{2}{|c|}{$\begin{array}{c}\text { ESCOLA } \\
\text { A1 }\end{array}$} & \multicolumn{2}{|c|}{$\begin{array}{c}\text { ESCOLA } \\
\text { A2 }\end{array}$} & \multicolumn{2}{|c|}{$\begin{array}{c}\text { ESCOLA } \\
\text { A3 }\end{array}$} & \multicolumn{2}{|c|}{$\begin{array}{c}\text { ESCOLA } \\
\text { B }\end{array}$} & \multicolumn{2}{|c|}{$\begin{array}{c}\text { ESCOLA } \\
\text { C }\end{array}$} & \multicolumn{2}{|c|}{$\begin{array}{c}\text { ESCOLA } \\
\text { D }\end{array}$} & \multicolumn{2}{|c|}{$\begin{array}{c}\text { ESCOLA } \\
\text { E }\end{array}$} \\
\hline & $\mathrm{N}$ & $\%$ & $\mathrm{~N}$ & $\%$ & $\mathrm{~N}$ & $\%$ & $\mathrm{~N}$ & $\%$ & $\mathrm{~N}$ & $\%$ & $\mathrm{~N}$ & $\%$ & $\mathrm{~N}$ & $\%$ \\
\hline ALTO & 1 & 5,3 & 7 & 50,0 & 2 & 12,5 & 11 & 47,8 & 4 & 26,7 & 2 & 15,4 & 2 & 22,2 \\
\hline MÉDIO & 18 & 94,7 & 2 & 14,3 & 2 & 12,5 & 8 & 34,8 & 3 & 20,0 & 2 & 15,4 & 6 & 66,7 \\
\hline BAIXO & 0 & 0,0 & 5 & 35,7 & 12 & 75,0 & 4 & 17,4 & 8 & 53,3 & 9 & 69,2 & 1 & 11,1 \\
\hline TOTAL & 19 & 100 & 14 & 100 & 16 & 100 & 23 & 100 & 15 & 100 & 13 & 100 & 9 & 100 \\
\hline
\end{tabular}

A1 - Escola A sala 1; A2 - Escola A sala 2; A3 - Escola A sala 3; B - Escola B; C - Escola C; D - Escola D; E - Escola E; $\mathrm{N}$ - Número de alunos.

Tabela 5 - Interferência do ruído na realização da atividade do ditado

\begin{tabular}{|c|c|c|c|c|c|c|c|c|c|c|c|c|c|c|}
\hline \multirow{2}{*}{$\begin{array}{l}\text { INTENSIDADE } \\
\text { DO RUÍDO }\end{array}$} & \multicolumn{2}{|c|}{$\begin{array}{c}\text { ESCOLA } \\
\text { A1 }\end{array}$} & \multicolumn{2}{|c|}{$\begin{array}{c}\text { ESCOLA } \\
\text { A2 }\end{array}$} & \multicolumn{2}{|c|}{$\begin{array}{c}\text { ESCOLA } \\
\text { A3 }\end{array}$} & \multicolumn{2}{|c|}{$\begin{array}{c}\text { ESCOLA } \\
\text { B }\end{array}$} & \multicolumn{2}{|c|}{$\begin{array}{c}\text { ESCOLA } \\
\text { C }\end{array}$} & \multicolumn{2}{|c|}{$\begin{array}{c}\text { ESCOLA } \\
\text { D }\end{array}$} & \multicolumn{2}{|c|}{$\begin{array}{c}\text { ESCOLA } \\
\qquad E\end{array}$} \\
\hline & $\mathrm{N}$ & $\%$ & $\mathrm{~N}$ & $\%$ & $\mathrm{~N}$ & $\%$ & $\mathrm{~N}$ & $\%$ & $\mathrm{~N}$ & $\%$ & $\mathrm{~N}$ & $\%$ & $\mathrm{~N}$ & $\%$ \\
\hline ALTO & 1 & 5,3 & 7 & 50,0 & 2 & 12,5 & 11 & 47,8 & 4 & 26,7 & 2 & 15,4 & 2 & 22,2 \\
\hline MÉDIO & 18 & 94,7 & 2 & 14,3 & 2 & 12,5 & 8 & 34,8 & 3 & 20,0 & 2 & 15,4 & 6 & 66,7 \\
\hline BAIXO & 0 & 0,0 & 5 & 35,7 & 12 & 75,0 & 4 & 17,4 & 8 & 53,3 & 9 & 69,2 & 1 & 11,1 \\
\hline TOTAL & 19 & 100 & 14 & 100 & 16 & 100 & 23 & 100 & 15 & 100 & 13 & 100 & 9 & 100 \\
\hline
\end{tabular}

A1 - Escola A sala 1; A2 - Escola A sala 2; A3 - Escola A sala 3; B - Escola B; C - Escola C; D - Escola D; E - Escola E; $\mathrm{N}-$ Número de alunos.

Tabela 6 - Compreensão das palavras do ditado pelos alunos

\begin{tabular}{|c|c|c|c|c|c|c|c|c|c|c|c|c|c|c|}
\hline \multirow{3}{*}{ DAS PALAVRAS } & \multirow{2}{*}{\multicolumn{2}{|c|}{$\begin{array}{c}\text { ESCOLA } \\
\text { A1 }\end{array}$}} & \multirow{2}{*}{\multicolumn{2}{|c|}{$\begin{array}{c}\text { ESCOLA } \\
\text { A2 }\end{array}$}} & \multirow{2}{*}{\multicolumn{2}{|c|}{$\begin{array}{c}\text { ESCOLA } \\
\text { A3 }\end{array}$}} & \multirow{2}{*}{\multicolumn{2}{|c|}{$\begin{array}{c}\text { ESCOLA } \\
\text { B }\end{array}$}} & \multirow{2}{*}{\multicolumn{2}{|c|}{$\begin{array}{c}\text { ESCOLA } \\
\text { C }\end{array}$}} & \multirow{2}{*}{\multicolumn{2}{|c|}{$\begin{array}{c}\text { ESCOLA } \\
\text { D }\end{array}$}} & \multirow{2}{*}{\multicolumn{2}{|c|}{$\begin{array}{c}\text { ESCOLA } \\
\text { E }\end{array}$}} \\
\hline & & & & & & & & & & & & & & \\
\hline & $\mathrm{N}$ & $\%$ & $\mathrm{~N}$ & $\%$ & $\mathrm{~N}$ & $\%$ & $\mathrm{~N}$ & $\%$ & $\mathrm{~N}$ & $\%$ & $N$ & $\%$ & $\mathrm{~N}$ & $\%$ \\
\hline SIM & 18 & 94,7 & 11 & 78,6 & 12 & 75,0 & 23 & 100 & 14 & 93,3 & 13 & 100 & 9 & 100 \\
\hline NÃO & 1 & 5,3 & 3 & 21,4 & 4 & 25,0 & 0 & 0.0 & 1 & 6,7 & 0 & 0,0 & 0 & 0,0 \\
\hline TOTAL & 19 & 100 & 14 & 100 & 16 & 100 & 23 & 100 & 15 & 100 & 13 & 100 & 9 & 100 \\
\hline
\end{tabular}


Tabela 7 - Percepção da intensidade vocal do professor pelos alunos durante as atividades de leitura de texto e ditado

\begin{tabular}{|c|c|c|c|c|c|c|c|c|c|c|c|c|c|c|}
\hline \multirow{3}{*}{$\begin{array}{c}\text { INTENSIDADE } \\
\text { VOCAL } \\
\text { UTILIZADA }\end{array}$} & \multirow{2}{*}{\multicolumn{2}{|c|}{$\begin{array}{c}\text { ESCOLA } \\
\text { A1 }\end{array}$}} & \multirow{2}{*}{\multicolumn{2}{|c|}{$\begin{array}{c}\text { ESCOLA } \\
\text { A2 }\end{array}$}} & \multirow{2}{*}{\multicolumn{2}{|c|}{$\begin{array}{c}\text { ESCOLA } \\
\text { A3 }\end{array}$}} & \multirow{2}{*}{\multicolumn{2}{|c|}{$\begin{array}{c}\text { ESCOLA } \\
\text { B }\end{array}$}} & \multirow{2}{*}{\multicolumn{2}{|c|}{$\begin{array}{c}\text { ESCOLA } \\
\text { C }\end{array}$}} & \multirow{2}{*}{\multicolumn{2}{|c|}{$\begin{array}{c}\text { ESCOLA } \\
\text { D }\end{array}$}} & \multirow{2}{*}{\multicolumn{2}{|c|}{$\begin{array}{c}\text { ESCOLA } \\
\text { E }\end{array}$}} \\
\hline & & & & & & & & & & & & & & \\
\hline & $\mathrm{N}$ & $\%$ & $\mathrm{~N}$ & $\%$ & $\mathrm{~N}$ & $\%$ & $\mathrm{~N}$ & $\%$ & $\mathrm{~N}$ & $\%$ & $\mathrm{~N}$ & $\%$ & $\mathrm{~N}$ & $\%$ \\
\hline FRACA & 4 & 21,1 & 3 & 21,4 & 1 & 6,3 & 2 & 8,7 & 0 & 0,0 & 1 & 7,7 & 0 & 0,0 \\
\hline ADEQUADA & 11 & 57,9 & 7 & 50,0 & 14 & 87,5 & 18 & 78,3 & 12 & 80,0 & 12 & 92,3 & 9 & 100,0 \\
\hline ALTA & 4 & 21,1 & 4 & 28,6 & 1 & 6,3 & 3 & 13,0 & 3 & 20,0 & 0 & 0,0 & 0 & 0,0 \\
\hline TOTAL & 19 & 100 & 14 & 100 & 16 & 100 & 23 & 100 & 15 & 100 & 13 & 100 & 9 & 100 \\
\hline
\end{tabular}

Tabela 8 - Percepção de fontes de ruído internas e externas pelo professor

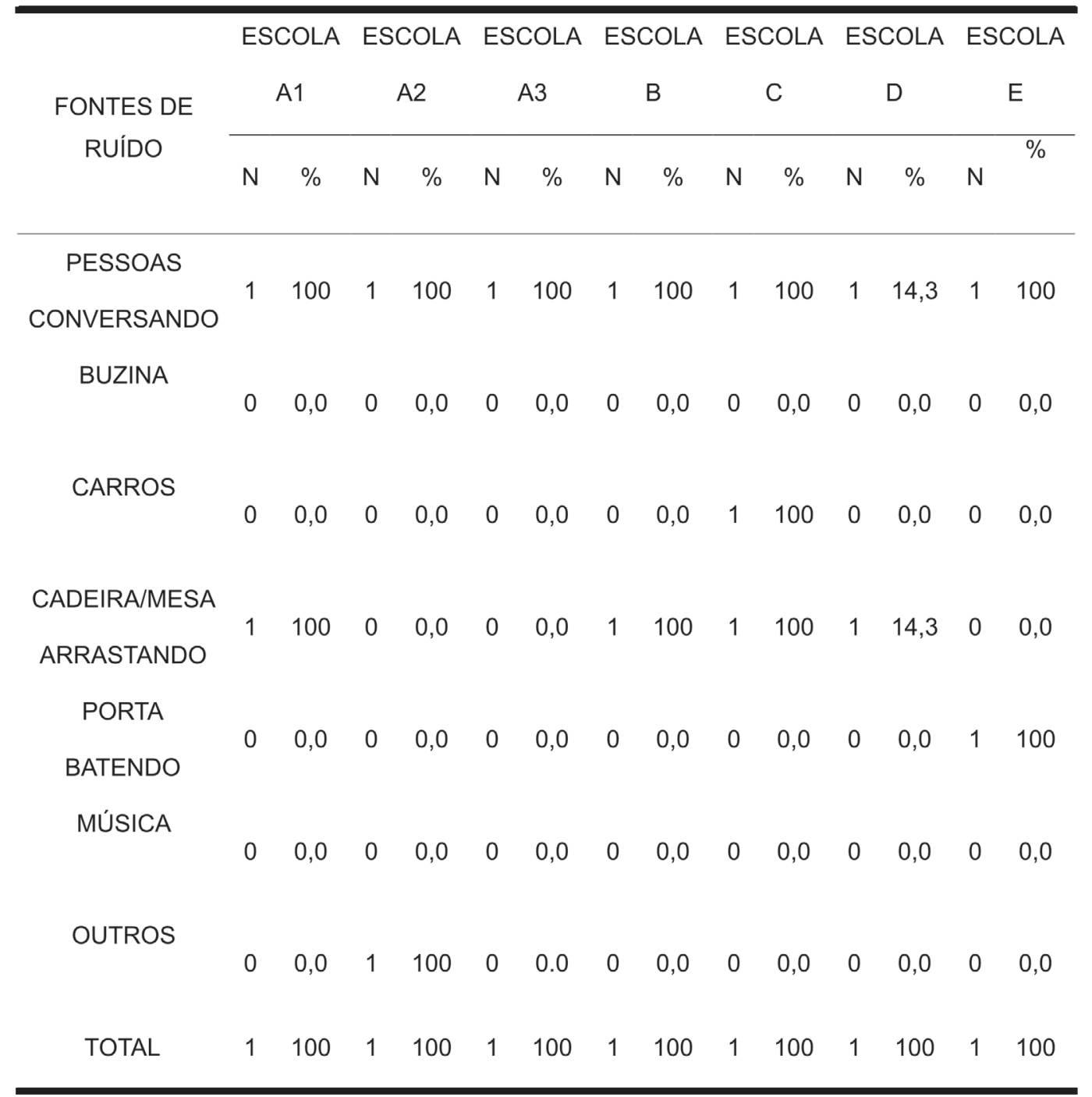

A1 - Escola A sala 1; A2 - Escola A sala 2; A3 - Escola A sala 3; B - Escola B; C - Escola C;

D - Escola D; E - Escola E; N - Número de professores. 


\begin{tabular}{|cccc|}
\hline & \multicolumn{2}{c}{ Lista de palavras } & \\
Babado & Favel & Pipoca & Vassoura \\
Bebida & Fofoca & Panela & Violão \\
Bigode & Fantasma & Peteca & Veludo \\
Boneca & Feijão & Pomada & Vizinho \\
Casaco & Gaiola & Sapato & Votação \\
Cocada & Geladeira & Sereia & Xarope \\
Cavalo & Girafa & Sorvete & Xícara \\
Cabelo & Goiaba & Sacola & Abacaxi \\
Dominó & Jabuti & Tapete & Lixeiro \\
Dentista & Jibóia & Tijolo & Zangado \\
Domingo & Jacaré & Tomate & Azarado \\
Damasco & Judiou & Tucano & Buzina \\
Fazenda & Lâmpada & & \\
\hline
\end{tabular}

Figura 1- Lista de palavras para o ditado

1. Durante a realização da atividade você percebeu outros tipos de sons além da fala da professora?

( ) $\operatorname{sim}$ ( ) não

2. Que tipo de sons você percebeu?

( ) pessoas conversando ( ) buzinas ( ) carros ( ) cadeiras/mesas arrastando ( ) porta batendo ( ) música ( ) outros

3. Esses sons eram?

( ) altos ( ) médios ( ) baixos

4. Esses sons interferiram na realização da atividade?

( ) sim ( ) não

5. Você compreendeu todas as palavras?

( ) $\operatorname{sim}$ ( ) não

6. Durante o ditado voz da professora estava:

( ) fraca ( ) adequada ( ) alta

Figura 2 - Questionário aplicado ao aluno 
1. Durante a aplicação do questionário você percebeu outros tipos de sons além da sua voz?

( ) $\operatorname{sim}($ ) não

2. Que tipo de sons você percebeu?

( ) pessoas conversando ( ) buzinas ( ) carros ( ) cadeiras/mesas arrastando ( ) porta batendo ( ) música ( ) outros

3. Esses sons eram?

( ) altos ( ) médios ( ) baixos

4. Esses sons interferiram na realização da atividade?

( ) $\operatorname{sim}($ ) não

5. Você precisou aumentar a intensidade vocal durante a aplicação da atividade?

( ) $\operatorname{sim}($ ) não

6. Após a aplicação da atividade você sentiu cansaço vocal?

Figura 3 - Questionário aplicado ao professor

\section{DISCUSSÃO}

Os níveis de ruído, avaliados nas escolas, variaram de 59,5 a 71,3 dB(A) (Tabela 1). Regulamenta a Associação Brasileira de Normas Técnicas (ABNT, 1987) ${ }^{9}$, na Norma Brasileira Registrada (NBR) 10152, que o nível de ruído para ambientes escolares não ultrapasse $50 \mathrm{~dB}(\mathrm{~A})$, sendo sugerido que os níveis de ruído indicados para o conforto acústi$c o$, em salas de aula, esteja entre 35 e $45 \mathrm{~dB}(\mathrm{~A})$. Assim, como este estudo, diversos outros realizados acerca da influência do ruído nas variadas atividades escolares também encontraram valores acima do recomendado tanto nas normas nacionais como internacionais ${ }^{1-4,15-19}$.

Esses níveis de ruído, embora estando acima do proposto pelas normas nacionais, não interferiram no resultado do ditado dos alunos (Tabela 1). Esse dado poderia ser explicado devido ao fato dos professores, principalmente das salas mais ruidosas (C e D), elevarem a voz durante a atividade, queixando-se posteriormente de cansaço vocal.

Observou-se que, 94,5\% dos alunos (Tabela 2) e $100 \%$ dos professores reportaram ouvir outro som em sala de aula. As fontes sonoras mais citadas tanto por alunos quanto por professores foram: pessoas conversando, cadeiras e mesas sendo arrastadas (Tabe- las 3 e 8). Os mesmos dados foram relatados por outros autores ${ }^{16}$ quando $75 \%$ dos pesquisados (162 sujeitos) relataram que o arrastar de cadeiras e a conversa dentro da sala de aula são as fontes sonoras mais aborrecedoras. Dentre as outras fontes de ruído, neste estudo, verificou-se barulhos de salas adjacentes e o bater de cortinas.

Ressalta-se, portanto, o fato de que a maioria dos ruídos de fundo é proveniente de fontes internas, pois somente $22,02 \%$ dos alunos e $14,3 \%$ dos professores relataram ouvir carros ou buzinas $(2,75 \%$ dos alunos), apesar de $40 \%$ das escolas estarem próximas a uma rodovia estadual. A afirmação de que o ruído interno é dominante sobre o externo também foi percebida por outros pesquisadores ${ }^{4,16}$. Nesse caso, salas acusticamente tratadas não seriam o recurso mais apropriado, uma vez que as fontes perturbadoras são internas. Programas de conscientização dos alunos para a importância do silêncio em salas de aula seria uma importante ferramenta de mudança do quadro de perturbação.

De uma maneira geral, as crianças divergem em opinião quanto ao fato de o ruído interferir na execução das atividades (Tabela 4) ainda que, a maioria dos alunos refere compreender todas as palavras do ditado (Tabela 5). Em um estudo, em que os níveis de ruído encontraram-se superiores ao recomendado 
(entre 58 e $69 \mathrm{~dB}(\mathrm{~A})$, a amostra (216 sujeitos) caracterizou o ruído como sendo moderadamente incômodo, e 72 sujeitos relataram que o ruído interferiu na realização da atividade ${ }^{16}$.

Um dado relevante refere-se à escola $D$, onde, apesar de apresentar o maior nível de ruído (71,3 $\mathrm{dB}(\mathrm{A})$ ), os alunos relataram que o ruído era baixo $(69,2 \%)$, não atrapalhava a execução das atividades $(84,6 \%)$ e compreendiam completamente as palavras do ditado (100\%) (Tabelas 5 e 6). Considerando o nível de ruído encontrado nessa escola, as crianças estariam em situação de escuta desfavorável, necessitando de maior atenção para reter a mensagem falada. Entretanto, o professor referiu precisar elevar a intensidade da voz e reclamou de cansaço vocal após a realização da atividade, o que justifica o fato de $92,3 \%$ dos alunos considerarem a intensidade vocal do professor adequada durante a realização da atividade (Tabela 7).

Dentre os professores que participaram da pesquisa, $100 \%$ afirmaram existir outras fontes sonoras. Apesar de todas as escolas estarem com níveis de ruído dentro de salas de aula acima do recomendado, dois dos sete professores consideraram o ruído baixo, e cinco, médio. É importante salientar que, nas duas escolas com maior nível de ruído 70,5 dB(A) (escola $C$ ) e 71,3 dB(A) (escola $D$ ), os professores relataram que os ruídos interferiram na atividade apre- sentando sintoma de alteração vocal. Estudos apontam o ruído como uma das principais causas de desconforto profissional na classe de professores e uma alta incidência de sintomas e patologias em graus variados como: sonolência, irritação, cansaço, nódulos vocais e edemas. Indicam ainda diferenças de incrementos de ruído de mais de $20 \mathrm{~dB}(\mathrm{~A})$ durante as aulas, indicando esforço vocal de professores enquanto falam ${ }^{3,6,17-19,27}$. Apesar de apenas 42,8\% dos professores considerarem que o ruído interfere nas atividades, $100 \%$ perceberam sua existência, o que sugere que todos os professores estão expostos aos riscos acima citados.

\section{CONCLUSÃO}

Apesar dos níveis de ruídos presentes nas salas de aula estarem acima do sugerido pelas normas nacionais, os mesmos não interferiram no resultado do ditado. Isso pode ser justificado pelo fato dos professores elevarem a intensidade da voz durante a execução da atividade. Como conseqüência, queixas de cansaço vocal foram relatados pelos professores das salas mais ruidosas.

Uma vez que a maioria dos ruídos de fundo desse estudo são de fontes internas, sugere-se a criação de um Programa de Educação Sonora Ambiental Escolar para todas as escolas avaliadas.

\begin{abstract}
Purpose: to evaluate noise level in the classrooms of first grade children as well as, to verify its interference during reading and dictation activities. Methods: measuring noise levels according to ANSI standards was performed in seven classrooms of five schools of the municipal network of teaching in the city of Urussanga, Santa Catarina during reading and dictation activities. Afterwards, a questionnaire was introduced to the students and teachers dealing with the interference of noise in the accomplished activities. 109 children participated in the survey and 59 were males and 50 females. Results: noise levels present in the classrooms varied from 59.5 to $71.3 \mathrm{~dB}(\mathrm{~A})$. Regarding the students' and teachers' perception of the noise, $94.5 \%$ of the students and $100 \%$ of the teachers noted other sound sources during the activities but just $52.39 \%$ of the students and $42.8 \%$ of the teachers affirmed an interference from the noise during the practice of the activities. Conclusion: it was observed that the noise level, despite being above proposed limits according to national standards, did not interfere in the results of the dictation. On the other hand, the teachers, mainly in the noisiest rooms, needed to raise their voices during the practice of their activities, complaining afterwards about vocal fatigue.
\end{abstract}

KEYWORDS: Noise; Noise Perception; Noise Effects; Learning

\section{REFERÊNCIAS}

1.Eniz AO. Poluição sonora em escolas do Distrito Federal. [Mestrado]. Brasília (DF): Pós-Graduação em Planejamento e Gestão Ambiental da Universidade Católica de Brasília; 2004.

2.Lacerda A, Marasca C. Níveis de pressão sonora de escolas municipais de Itapiranga - Santa Catarina.
Pró-Fono R Atual Cient. 2001; 13(2):277-80.

3. Knecht HA, Nelson PB, Feth LL. Background noise levels and reverberation times in unoccupied classrooms: predictions and measurements. Am J Audiol, 2002; 11:65-7.

4.Shield B, Dockrell JE. External and internal noise surveys of London primary schools. J Acoust Soc Am. 2004; 115(2):730-8. 
5. Seep B, Glosemeyer R, Hulce E, Linn M, Aytar P. Acústica em sala de aula. Rev Acúst Vibr. 2002; 29:2-22.

6. American Speech-Language Hearing Association (ASHA). Acoustics in educational settings: position statement. [cited 2006 jun 25]. Disponível em: URL: http://www.asha.org/members/deskref-journals/ deskref/default

7.Vilkman E. Occupational safety and health aspects of voice and speech professions. Folia Phoniatr Logop. 2004; 56(4):220-53.

8. Preciado JÁ, Garcia TR, Infante JC. Prevalence of voice disorders among educational professionals: factors contributing to their appearance or their persistence. Acta Otorrinolaringol.1998; 49(2):137-42. 9. Resolução do Conama № 001, de O8 de março de 1990. [cited 2006 set 05]. Disponível em: URL: http:/ /www.lei.adv.br/001-90.htm

10. Associação Brasileira de Normas Técnicas (ABNT). NBR 10152: Níveis de ruído para conforto acústico - procedimento. Rio de Janeiro; 1987.

11. American National Standards Institute (2002). Acoustical performance criteria, design requirements and guidelines for schools. ANSI S12-60.

12. Noise Regulation. [cited 2006 may 31]. Disponível em: URL: http://en.wikipedia.org/wiki/ Noise_regulation

13. Perturbações Sonoras. Directiva 2002/49/CE do Parlamento Europeu e do Conselho, de 25 de Junho de 2002, relativa à avaliação e gestão do ruído ambiente. [cited 2006 may 31]. Disponível em: URL: http:/ /europa.eu.int/scadplus/leg/pt/lvb//21180.htm 14. Celani AC, Bevilacqua MC, Ramos CR. Ruído em escolas. Pró-Fono R Atual Cient. 1994; 6(2):1-4.

15. Lundquist $P$, Holmberg K, Burström L, Landström $U$. Sound levels in classrooms and effects on selfreported mood among school children. Percept Mot Skills. 2003; 96(3):1289-99.

16. Lundquist $P$, Holmberg $K$, Landström U. Annoyance and effects on work from environmental noise at school. Noise Health. 2000; 2(8):39-46.

17. Libardi A, Gonçalves CGO, Vieira TPG, Silveiro KCA, Rossi D, Penteado RZ. O ruído em sala de aula e a percepção dos professores de uma escola de ensino fundamental de Piracicaba. Distúrb Comum. 2006; 18(2):167-78.

18. Lacerda A, Marasca C. Percepção auditiva de alunos e professores dos níveis de pressão sonora presente nas escolas e suas implicações na prática escolar. Pró-Fono R Atual Cient. 2002; 14(1):85-92. 19. Jamieson DG, Kranjc G, Yu K, Hodgetts WE. Speech intelligibility of young school-aged children in the presence of real-life classroom noise. J Am Acad Audiol. 2004: 15(7):508-17.

20. Hygge S. A comparison between the impact of noise from aircraft, road traffic and trains on long-term recall and recognition of a text in children aged 12-14 years. Schriftenr Ver Wasser Boden Lufthyg. 1993; 88:416-27.

21. Hygge S, Boman E, Enmarker I. The effects of road traffic noise and meaningful irrelevant speech on different memory systems. Scand J Psychol. 2003; 44(1):13-21.

22. Matsui T, Stansfeld M, Haines M, Head J. Children's cognition and aircraft noise exposure at home: the West London Schools Study. Noise Health. 2004; 7(25):49-58.

23. Clark C, Martin R, Van Kempen E, Alfred T, Head J, Davies HW et al. Exposure-effect relations between aircraft and road traffic noise exposure at school and reading comprehension: the RANCH project. Am J Epidemiol. 2006; 163(1):27-37.

24. Stansfeld SA, Berglund B, Clark C, Lopez-Barrio I, Fischer P, Ohrstrom E et al. Aircraft and road traffic noise and children's cognition and health: a crossnational study. Lancet. 2005; 365(9475):1942-9.

25. Dreossi RCF, Momensohn-Santos T. O ruído e sua interferência sobre estudantes em uma sala de aula: revisão de literatura. Pró-Fono R Atual Cient. 2005; 17(2):251-8.

26. Associação Brasileira de Normas Técnicas (ABNT). NBR 10151: Avaliação do ruído em áreas habitadas visando o conforto das comunidades - procedimento. Rio de Janeiro, 1987.

27. Pekkarinen E, Viljanen V. Acoustic conditions for speech communication in classrooms. Scand Audiol. 1991; 20(4):257-63.

RECEBIDO EM: 02/02/07

ACEITO EM: 05/03/2007

Endereço para correspondência:

Bianca Simone Zeigelboim

Rua Gutemberg, 99 - 9adar

Curitiba-PR

CEP: 80420030

Tel/Fax: (41) 33317807

E-mail: bianca.zeigelboim@utp.br 